\title{
Aircraft passenger comfort evaluation: sitting and standing passengers in commercial cabin
}

\author{
Clélia Moraes ${ }^{1, *}$ \\ ${ }^{1}$ PMA, Prefeitura Municipal de Araraquara, Coordenadoria de Mobilidade Urbana, Brazil
}

\begin{abstract}
This research investigates the evaluation of passenger comfort during a cruise airplane trip. The flow fields in the comfort design in commercial aircraft create contour conditions for the diffusers, cabinets and geometry cabin, responsible for providing a healthy environment to the passengers. The objective of this work is to characterize the airflow by measuring the velocity field and the air temperature inside the cabin. Based on the actual data, a computational fluid dynamics (CFD) analysis was performed using the Autodesk programming language for the simulations, in order to obtain information about the possible standards of easy and seated comfort for the passengers. The results of particle dispersion in the cockpit showed great influence of the ventilation system and the location in the aircraft where people generate the particles. Based on these results, the internal layout of the BWB2 airplane, also known as "Flying Wing" was projected. The projected cabin furniture features ventilation in order to attend the passenger's need in flight. It is noted that the incipient individualization of the passenger's thermal comfort configures one of the biggest problems faced by the airlines. Consequently, It is a possible differential for competition between airlines.
\end{abstract}

\section{Introduction}

This article presents a comparative study of thermal comfort by means of computational fluid dynamics (CFD) simulations in an empty aeronautical cabin and thermal manikin seated and standing. Thus, it can provide detailed information on thermal comfort that it is impossible to obtain in experimental research. We discuss several issues of CFD studies with the empty environment and with thermal manikins (CTMs) with the actual dimensions of a person. The simulations are results of the air temperature of the boundary conditions of the fluid and solid properties of the interior of the aircraft cabin. The results of the CFD simulations will provide reliable parameters of thermal comfort for the design of the cabin layout of the commercial passenger aircraft BWB2, also known as "flying wing", thus respecting cabin geometry. The model of this aircraft was developed by H.D.C.Muñoz. Therefore this research is justified due to the air quality and its impact on the human during the cruise that determine elements of the aeronautical comfort design and exert strong influences on the thermal conditions of the passenger. In addition, the importance of designing the internal environment of the airplane cabin and establishing specific norms and standards for such an environment and its particularities became the subject of discussion among several researchers and the requirement of passengers, travel agencies and airlines that competitiveness among airlines. Based on these parameters, the design of the
BWB2 "Flying Wing" was designed with ventilation and air temperature customized to meet the requirements of thermal comfort of the cabin of the aircraft with respect to the movement of the particular air and the comfort of the passenger during the flight.

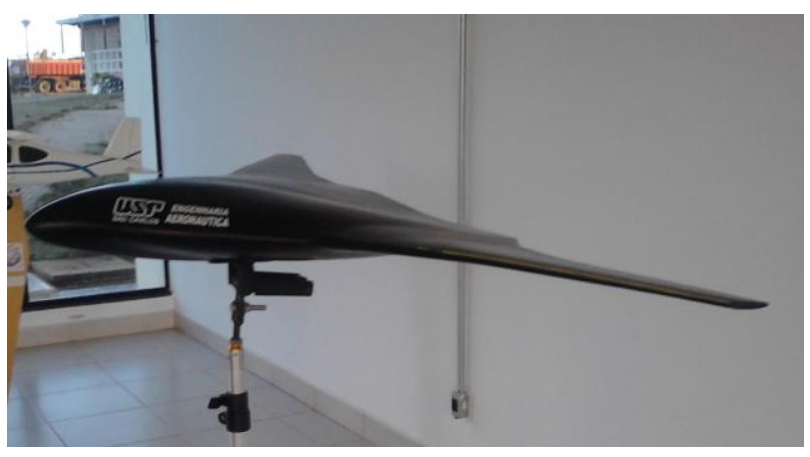

Fig. 1. BWB2 Model

\section{Objective}

The objective is to perform a CFD thermal analysis to compare numerical results in an empty aircraft cabin with a thermal manikin sitting in an armchair and standing in the aero cabin. The overall thermal result will allow reliable parameters to be obtained to design the personalities of the BWB2 aircraft, respecting the cabin

arqclelia@hotmail.com 
geometry in order to guarantee the passengers' thermal comfort.

\section{Input Data}

In order to perform the simulations, the Autodesk-CFD computational fluid dynamics package was used, with mesh generation tools (preprocessing), solution of the discretized conservation (solver) and post-processing equations, where it was possible to be calculated the current lines, profiles and animations. The data used in the CFD simulation of the commercial aircraft cockpit of the e-170 aircraft will be described in Figures 1 and 2.

\begin{tabular}{|c|c|c|c|}
\hline \multicolumn{4}{|c|}{ Material Environment } \\
\hline \multicolumn{4}{|c|}{$\begin{array}{l}\text { Fixed } \\
\checkmark \text { Use scenario environment }\end{array}$} \\
\hline \multicolumn{4}{|c|}{$\begin{array}{l}\text { Properbes for Air (variable) } \\
\text { Environment: } 101325 \mathrm{~Pa}, 19.85 \text { Celsius (from scenario) }\end{array}$} \\
\hline Property & Value & Units & $\begin{array}{l}\text { Underlying } \\
\text { variation }\end{array}$ \\
\hline Density & 1.20473 & $\mathrm{~kg} / \mathrm{m} 3$ & Equation of State \\
\hline Viscosity & $1.817 \mathrm{e}-05$ & Pa-s & Constant \\
\hline Conductivity & 0.02563 & W/m-k & Constant \\
\hline Specific heat & 1004 & $J / k g-k$ & Constant \\
\hline $\mathrm{Cp} / \mathrm{Cv}$ & 1.4 & none & Constant \\
\hline Emissivity & 1 & none & Constant \\
\hline Wall roughness & 0 & meter & Constant \\
\hline \multirow[t]{2}{*}{ Phase } & 0 & & Vapor Pressure \\
\hline & & OK & Cancel \\
\hline
\end{tabular}

Fig. 2. Physical input data (01)

\begin{tabular}{|l|l|l|}
\hline Region: 01 & $\begin{array}{l}\text { Temperature } \\
\text { imposed }\end{array}$ & $297 \mathrm{k}$ \\
\hline Region: 02 & $\begin{array}{l}\text { Condition of } \\
\text { temperature, } \\
\text { speed and } \\
\text { pressure }\end{array}$ & $\begin{array}{l}\mathrm{T}=293 \mathrm{k}, \\
\mathrm{Vx}=-0.5 \mathrm{~m} / \mathrm{s}, \\
\mathrm{P}=0.0 \mathrm{~Pa}\end{array}$ \\
\hline Region: 03 & $\begin{array}{l}\text { Output pressure } \\
\text { condition }\end{array}$ & $\mathrm{Pa}=0.0 \mathrm{~Pa}$ \\
\hline Region 04 & $\begin{array}{l}\text { Condition of } \\
\text { Transf. of heat } \\
\text { Fluid-Solid }\end{array}$ & $\mathrm{k}=0.1 \mathrm{~W} / \mathrm{m}^{\wedge} 2 \mathrm{k}$ \\
\hline
\end{tabular}

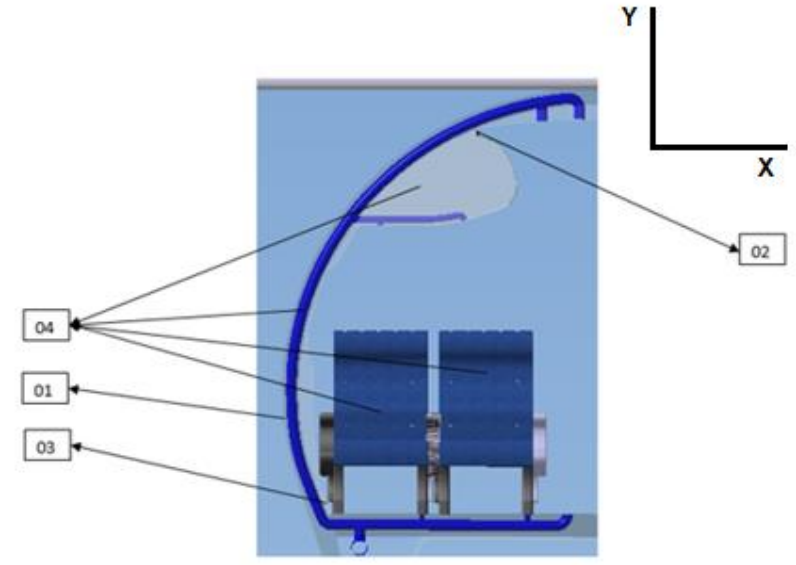

Fig.3. Contour conditions (02).

Fig. 4. Presentation of the contour conditions of the aircraft cabin e-170

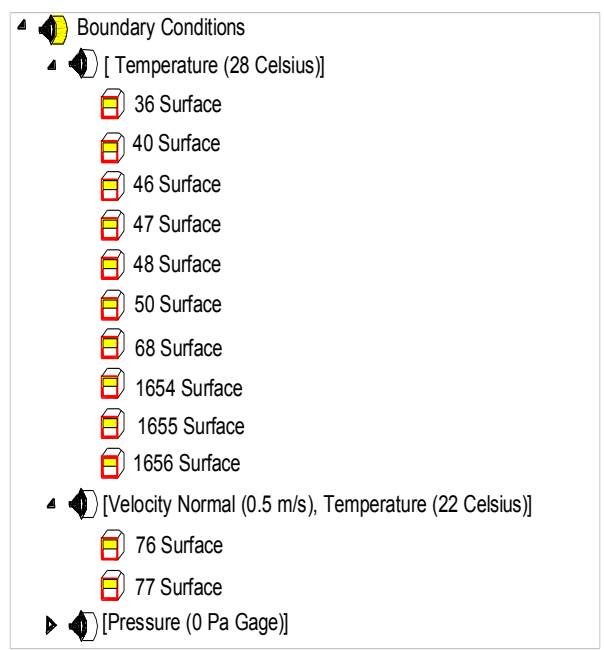

Fig. 4. Contour conditions (02).

Figure 5. The surface of the mesh. A fine grid is used in the area with large gradients to minimize false diffusion and dispersive errors, to optimize the grid. 


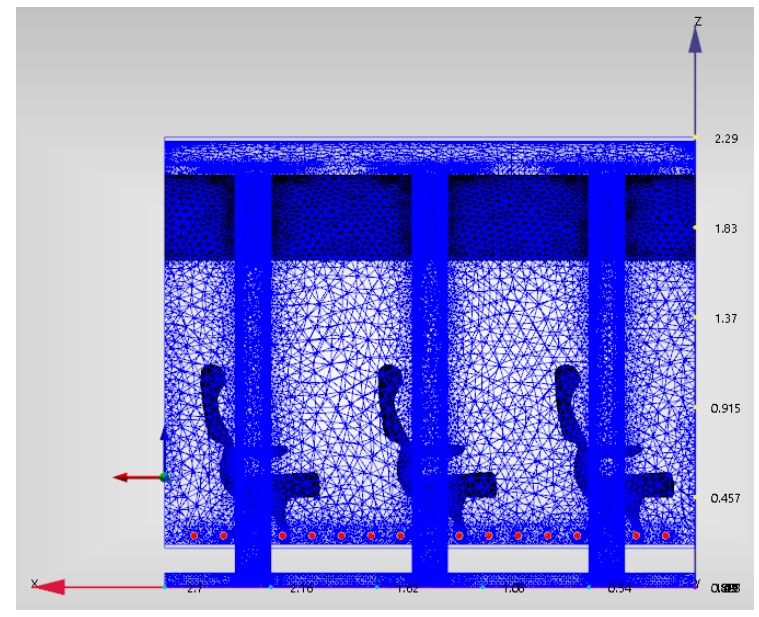

Fig. 5. Mesh Surface

\section{Results}

\subsection{Empty cabin}

Figure 5 - 11. Represents the air supply diffuser using a computational mesh for fluid domain mesh demonstration. Figure 6 shows the empty cabin airspeed.

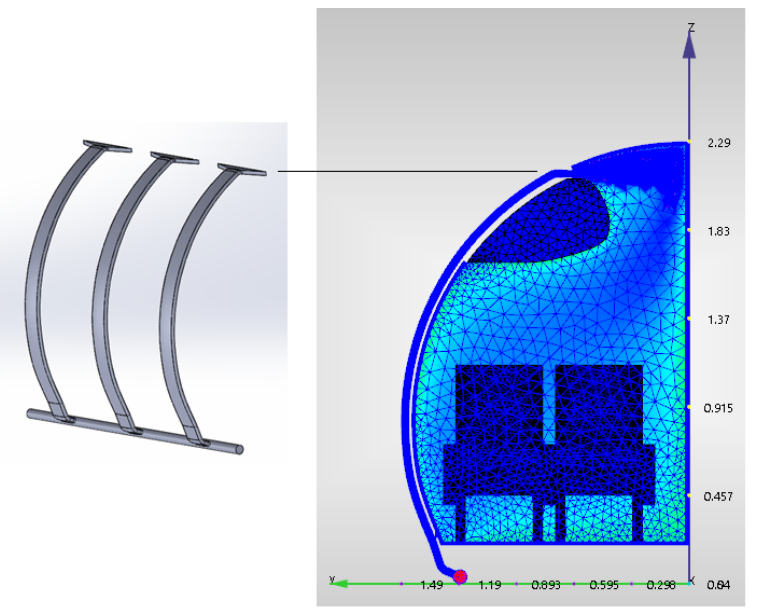

Fig. 6. Representation of air supply diffuser
(1) Velocity Magnitude - $\mathrm{m} / \mathrm{min}$

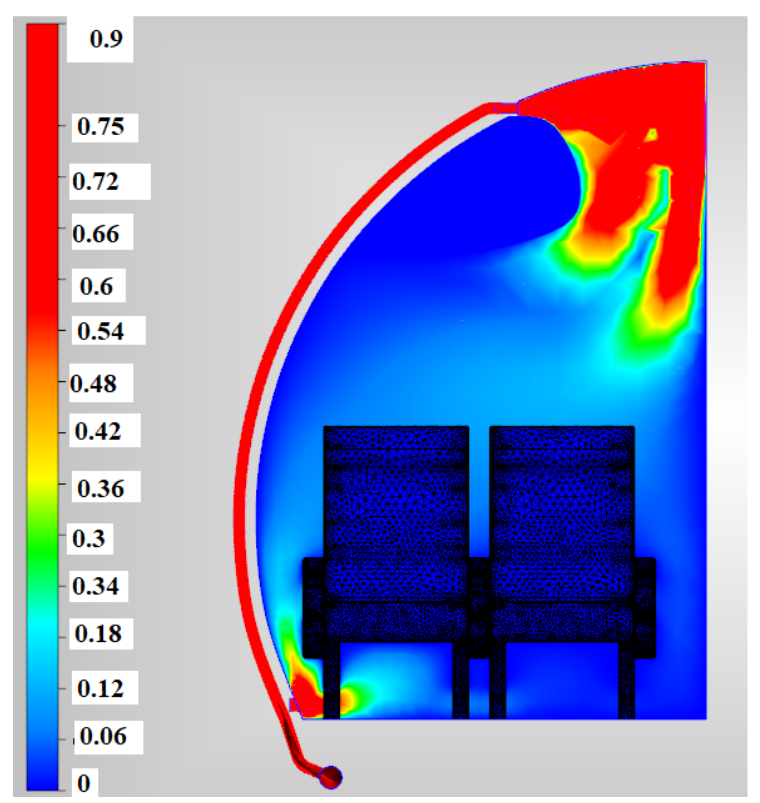

Fig. 7. Empty cabin airspeed

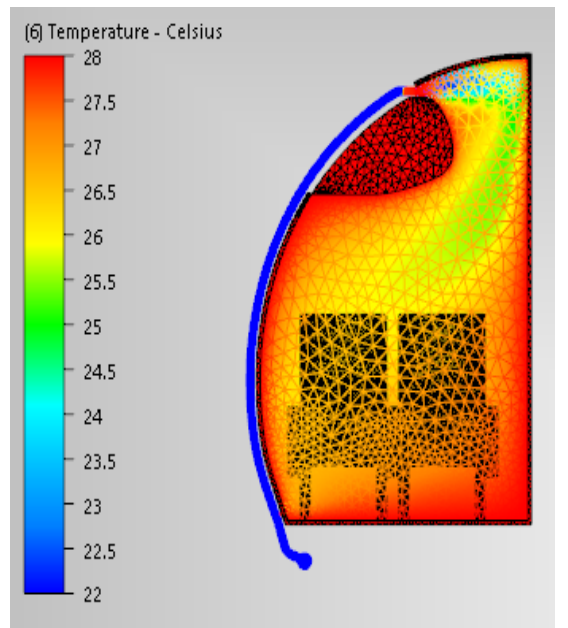

Fig. 8. Cabin air temperature is empty

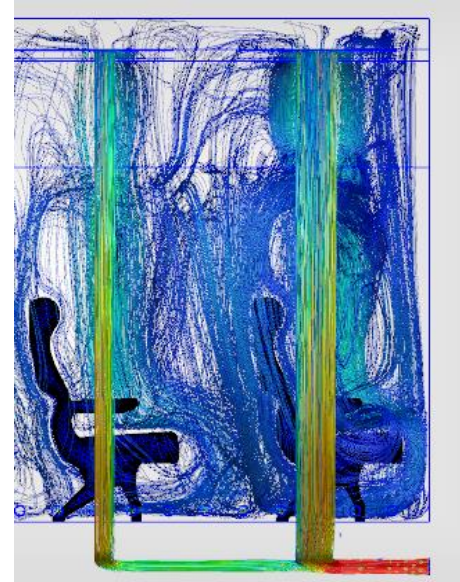

Fig. 9. Cutting the plane for empty cabin fluid demonstration. (2) 


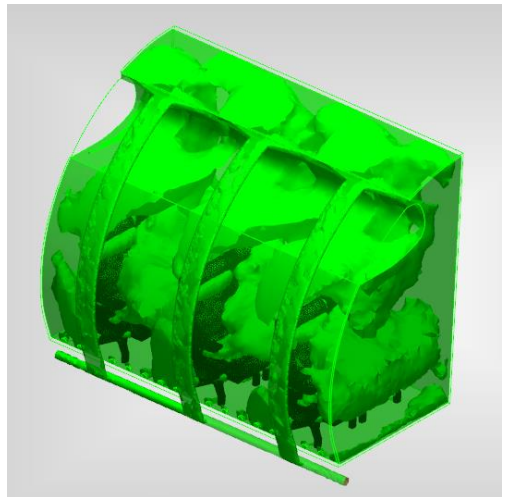

Fig. 10. Iso Surface: are surfaces that represent points of a constant value. As an instance of temperature and air velocity.

The graphs in Figure 10 and 11 are generated by the software to display the result of air temperature and velocity of the empty cabin.

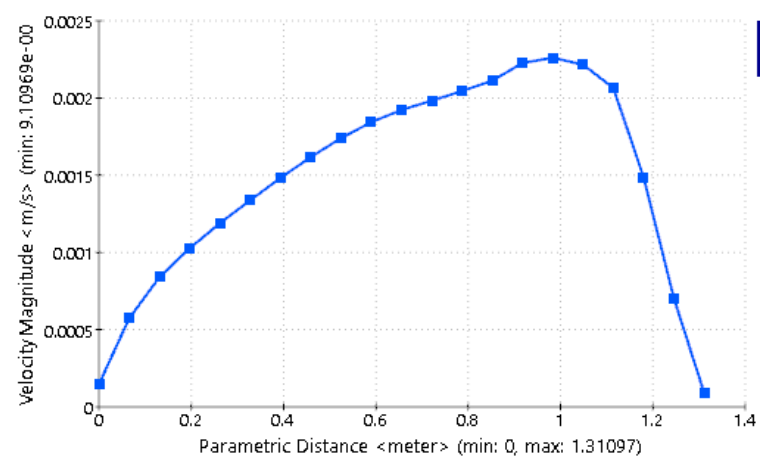

Fig. 11. Graph of empty cabin airspeed

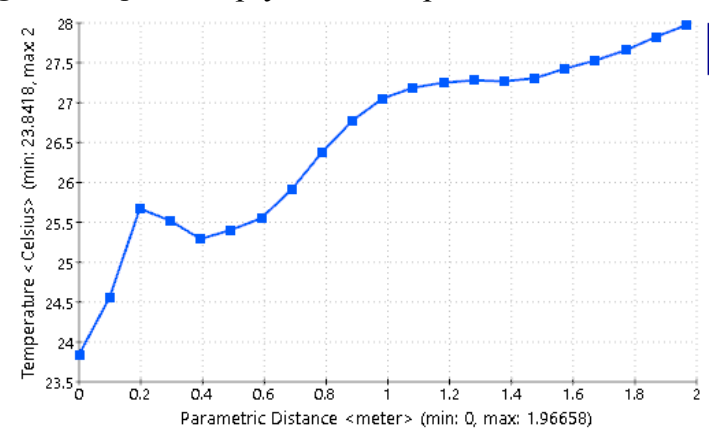

Fig. 12. Graph of the air temperature of the empty cabin. In the absence of the human being the first observation is that the lower air intake does not seem to influence or influence very little the temperature of the air near the ground, not even in the immediate surroundings of the entrance. The behavior of the temperature field in Figure 7 shows the variation in the region in which passengers would be seated up to $2^{\circ} \mathrm{C}$. This asymmetry, with the lowest temperature in the head region and the heated feet, provides discomfort in the space users.

\subsection{Front view of the cabin with sitting mannequin}

The CFD simulations performed with the seated manikin are presented in Figures 12 - 16.

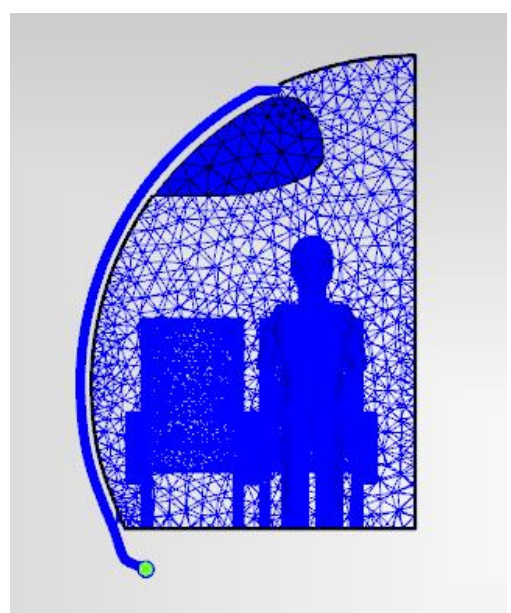

Fig. 13. Cabin mesh with sitting passenger.

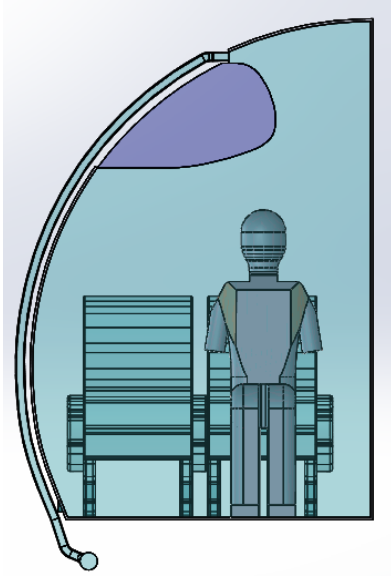

Fig. 14. Front view of cab geometry with passenger sitting

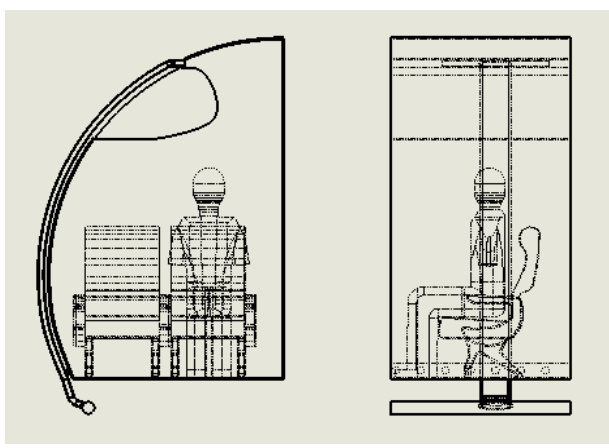

Fig. 15. Cab Flow Lines with Seated Mannequin 


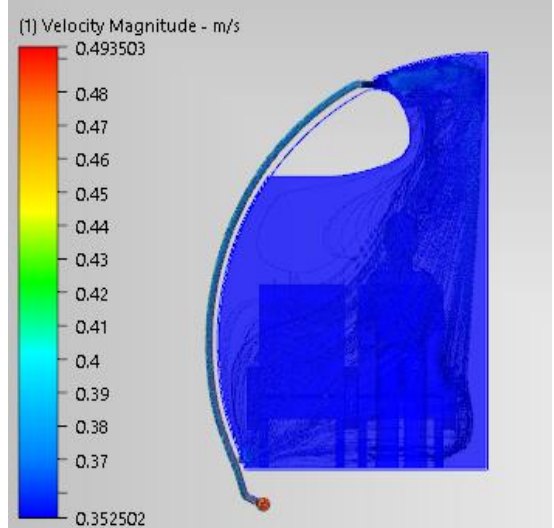

Fig. 16. Airspeed with passenger in seat $(0.35-0.49 \mathrm{~m} / \mathrm{s})$

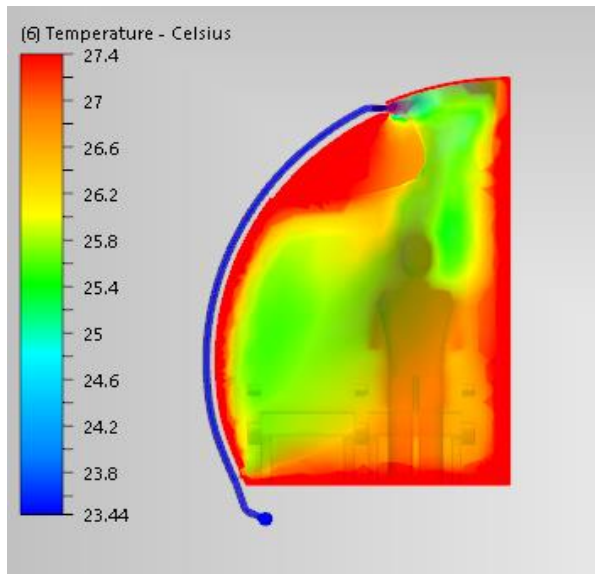

Fig. 17. Air temperature with sitting passenger (23.4$\left.27.4^{\circ} \mathrm{C}\right)$

For these results, the lower air intake allows the passenger near the window to be exposed to a more balanced scenario, a fact that does not occur with the passenger in the corridor.

\subsection{Front view of the cabin with standing manikin}

The CFD simulations performed with the seated manikin are presented in Figures 17 - 22.

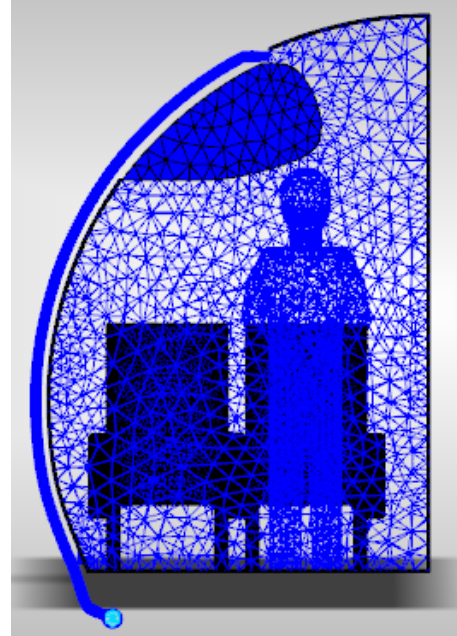

Fig. 18. Cabin mesh with standing passenger

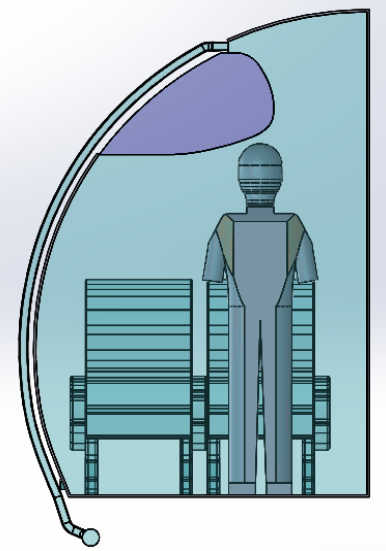

Fig. 19. Side view of the cabin with standing manikin
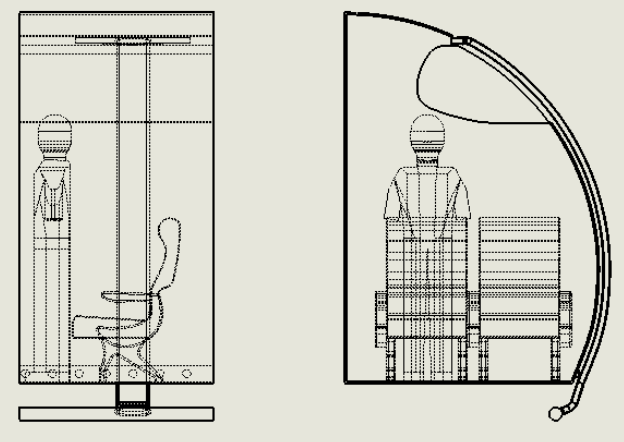

Fig. 20. Cabin flow lines with standing manikin 


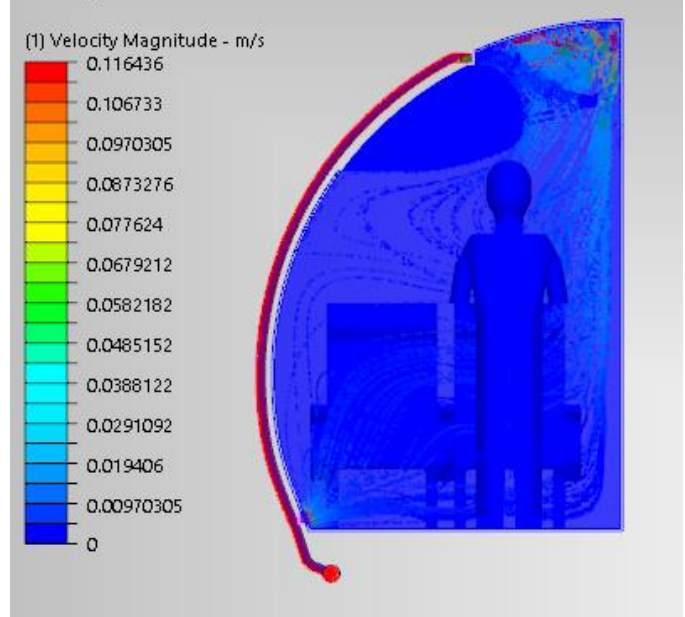

Fig. 21. Airspeed with standing passenger

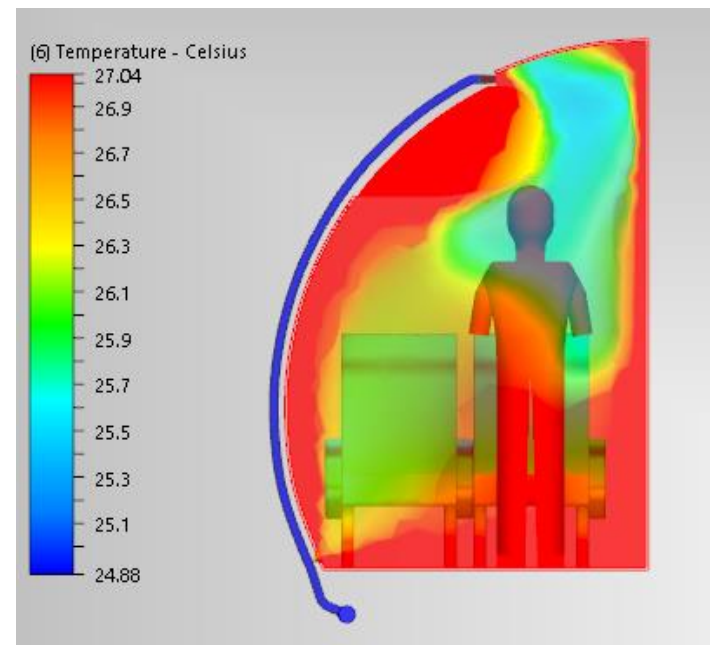

Fig. 22. Cabin temperature display with standing passenger

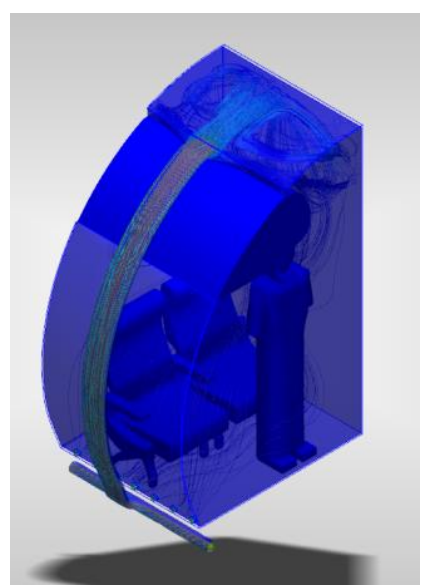

Fig. 23. Iso surface of the same air flow line with standing passenger

In the cockpit with the passenger standing: The variation reaches $2.5^{\circ} \mathrm{C}$ between head and foot temperature. This difference represents discomfort. We enquire two questions: the individual functions as an obstacle, right? Does it emit heat from your body?

This is a position, say, sporadic, since it happens when the passenger gets up, but soon after he should sit down.
Maybe flight attendants are more exposed to this scenario. The regions of wind shade, as expected, have higher temperatures. Nevertheless, the presence of the (non-existent) division in the middle of the cabin seems to force the change of air direction creating a different dynamic from what actually occurs. Is it possible to simulate the entire cabin?

\section{Conclusion}

The results of this work present a model based on computational simulation in CFD with parameters of air temperature and velocity distribution in real cabin environment of empty commercial aircraft, with passenger sitting and standing. The importance of researching the standing passenger due to the fact that during the flight the passengers rise and circulate in the cabin and the flight attendants remain standing distributing food for the passengers.

It is verified that the result of these simulation in CFD present different profiles of air temperature and velocity for each form of occupancy of the empty cabin or with passengers having a new variable, the human breathing. Factors that result in different particle distribution patterns in the cabin. Therefore, the ceiling ventilation system promotes a greater dispersion of particles throughout the cabin, due to the characteristics of the mixture of this type of ventilation. It is observed that because of the characteristics of the air mixture of this type of ventilation there is a greater concentration of particles in the cabin in the ventilation system, by indicating a lower efficiency in the removal of air from the air cabin.

It concludes with the development of the research the dispersion of air particles receives great influence of the ventilation system used and the point of injection of particles. These factors became key parameters for developing the custom ventilation design for the commercial passenger aircraft BWB2, known as the "Flying Wing". It is important to study the environmental comfort, to verify the real thermal behavior of the user of commercial aircraft. In view of the need to investigate air diffusers, responsible for passenger discomfort and the transmission of diseases such as the so-called SARS, and the challenges that are imposed on the intentions of designing a healthy and comfortable environment in the cabins.

Based on research on personified ventilation (PV) and floor air inflation (UFAD), the furniture design of the commercial wing aircraft was developed, which are presented in Figure 23 through Figure 27, especially considering the point view of the passenger and emphasizing above all the concepts of human thermal sensation. 


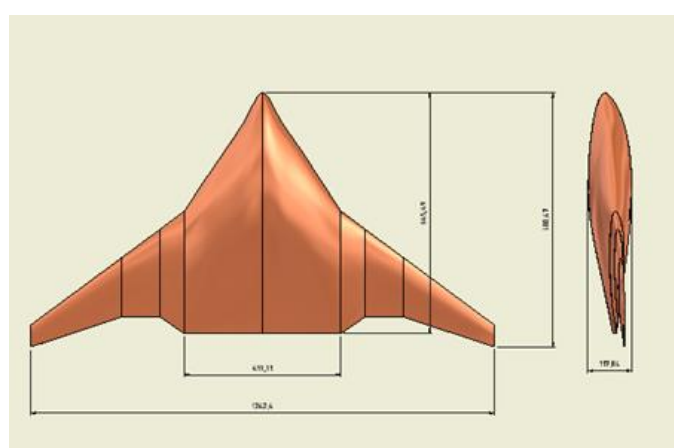

Fig. 24. Flying Wing Project
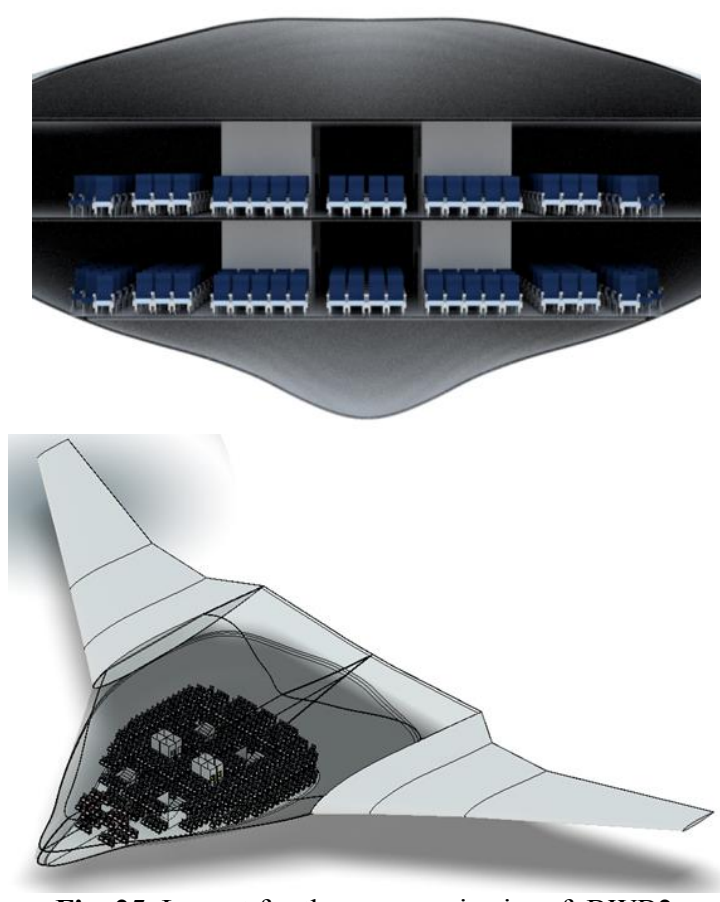

Fig. 25. Layout for the supersonic aircraft BWB2

The layout of the ergonomic armchair is shown in Figure 25. The kitchen design is shown in Figure 26 and the bathroom design is in Figure 27.
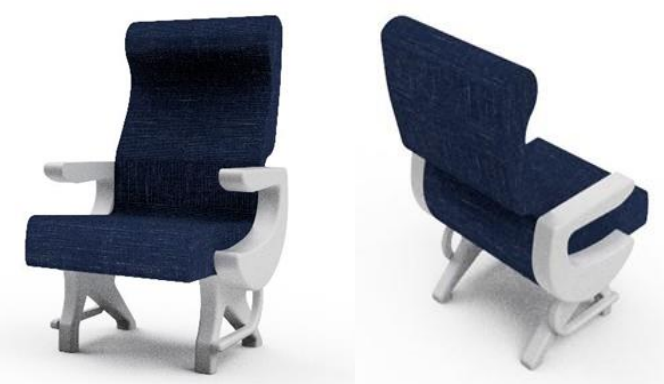

Fig.26. Perspectives of the economic armchair

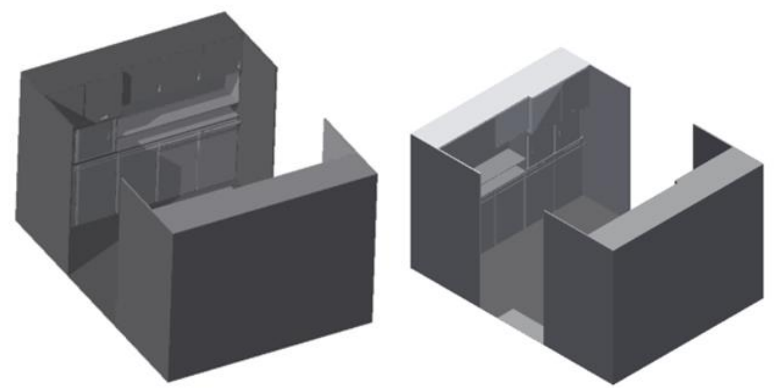

Fig. 27. Kitchen Perspectives

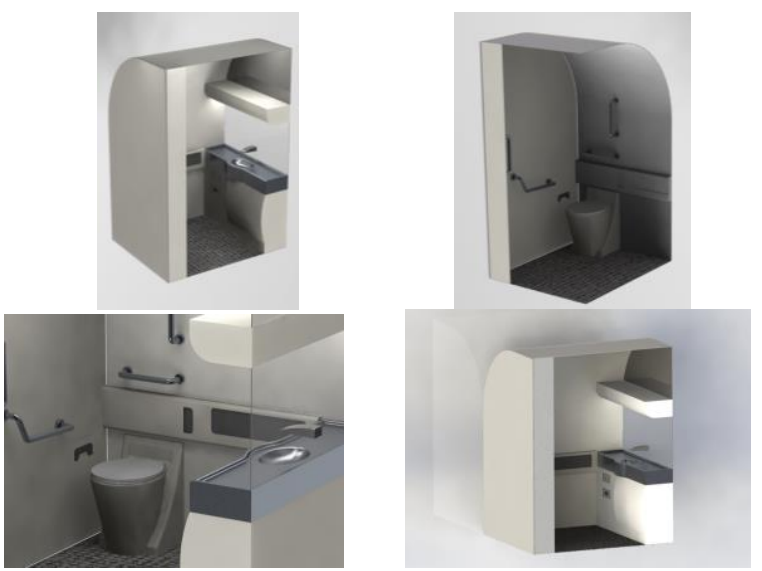

Fig. 28. Bathroom Perspectives

\subsection{Future Work}

CFD analysis module within CATIA software and Fanger method for reshaping the internal layout of the aircraft and remodeling of the air conditioning duct system da Flying Wing "BWB2"

\section{Future work}

City Hall of Araraquara - São Paulo

Technological Research Institute, Brazil

Aeronautical Engineering Department, University of São Paulo, Brazil

\section{References}

1. CONCEIÇÃO, S. T., Contaminação aérea em cabines climatizadas: Processo de avaliação e análise da influência de sistema de ventilação personalizado. Tese de Doutorado. Departamento de Engenharia Mecânica, Escola Politécnica da USP, São Paulo, 218p.(2012)

2. FABICHAK, D.J. ; SILVA, E.S. ; MOREL, J.C.O. e TRIBESS, A. Dispersão de partículas em cabine de aeronave com insuflamento convencional pelo teto e pelo piso. Escola Politécnica da Universidade de São Paulo http://www.umc.br/artigoscientificos/artcient-0016.pdf 
3. LOMBARDO, David A., Advanced aircraft systems: understanding your airplane - TAB Books, 1993.

4. MORAES, Clélia Mendonça; Gomes, Narciso Grimaldi. In Clima 2016 WellBeing Indoors 10th Rheva World Congress, 2013, Aalborg, Denmark 2016.

5. MORAES, Clélia Mendonça de, Thermal comfort in the classroom in Brazil: experimental and numerical analysis / Clélia Mendonça de Moraes. Campinas, SP: [s.n.], 2009.

6. Nielsen, P.V.; Damsgaard, C.; Liu, Li, Jensen,R., Test of Different Air Distribution Concepts for a Single-Aisle Aircraft Cabin In Clima 2013 WellBeing Indoors 9th Rheva World Congress, 2013, Prague, Czech Republic 2013. Proccedings 832. 